\title{
Assessing the Spatial Concentration of Urban Crime: An Insight from Nigeria
}

\author{
Faisal Umar ${ }^{1}$ (D) . Shane D. Johnson² ${ }^{2}$ James A. Cheshire ${ }^{3}$ \\ Published online: 6 January 2020 \\ (c) The Author(s) 2020
}

\begin{abstract}
Objective Research demonstrates that crime is concentrated. This finding is so consistent that David Weisburd refers to this as the "law of crime concentration at place". However, most research on crime concentration has been conducted in the US or European cities and has used secondary data sources. In this study, we examine whether the law of crime concentration applies in the context of sub-Saharan Africa using primary data.

Methods A crime victimization survey was used to collect data in the city of Kaduna (Nigeria). Using these data, the concentration of crime (breaking-and-entering and domestic theft) was examined at the household, street segment, and neighborhood levels. Specifically, variants of a Lorenz curve and the Gini index (GI) were used to examine whether crime concentrates at these different spatial scales and if such concentration reflects anything beyond the spatial distribution of opportunity for these types of offenses.

Results Crime was found to concentrate at all spatial scales, and having accounted for expectation, given the distribution of opportunity, crime was most concentrated at the household level, closely followed by street segments. It was relatively less concentrated at the neighborhood level.

Conclusion The current study extends previous research in a number of ways. It shows that the law of crime concentration at place applies in a very different context to most previous work. Unlike previous studies, we use primary data collected specifically to test the law, avoiding problems associated with the dark figure of crime. Moreover, the findings persist after accounting for crime opportunity.
\end{abstract}

Keywords Crime concentration $\cdot$ Breaking and entering $\cdot$ Theft $\cdot$ Kaduna $\cdot$ Nigeria $\cdot$ Monte Carlo simulation

Shane D. Johnson

shane.johnson@ucl.ac.uk

Faisal Umar

fumar@abu.edu.ng

1 Department of Urban and Regional Planning, Ahmadu Bello University, Main Campus, Zaria, Nigeria

2 Department of Security and Crime Science, University College London, 35 Tavistock Square, London WC1H 9EZ, UK

3 Department of Geography, University College London, Gower Street, London WC1E 6BT, UK 


\section{Introduction}

Research concerned with the distribution of urban crime is not new and consistently demonstrates that it is concentrated (e.g. Pierce et al. 1988; Sherman et al. 1989; Weisburd et al. 1992, 2004; Johnson 2010; Weisburd et al. 2012; Bowers 2014; Weisburd and Amram 2014; Curman et al. 2015; Mazeika and Kumar 2017). In fact, this empirical regularity has been demonstrated so consistently, and the findings are so similar (see below), that David Weisburd refers to it as the "law of crime concentration at place". However, much of the empirical testing of this law has been focused on Euro-American settings-cities in Western Europe and North America. During his 2014 Sutherland lecture (see: Weisburd 2015), Weisburd emphasized the need for wider empirical testing of the law beyond the EuroAmerican context, perhaps in other countries or cities-raising an interesting questionare there circumstances or contexts for which this law does not apply? This study seeks to address this question by broadening the existing literature on the concentration of crime at place in two ways.

First, the study focuses on sub-Saharan Africa; an understudied region and one where cities often develop with little or no centralized physical planning. Unlike settings in North America and Western Europe, cities in this context are often characterized by irregular plot layouts with narrow streets that are mostly unpaved. Moreover, they often have features such as gated streets, and petty trading takes place within residential premises, which is largely non-existent in typical Euro-American settings. Neighborhoods differ too with the practice of gating communities commonplace in Nigeria. The Nigerian culture of 'brother's keeper' - that neighbors must care for each other-also contrasts with Euro-American culture and encourages greater social interaction between neighbors, thus, enhancing social control (at least theoretically). Given this unique environmental setting, combined with a distinct socio-cultural orientation, it is plausible that the distribution of crime in this context may be expected to exhibit a different pattern to what has been observed in Europe and North America. Consequently, it is unclear whether the law will apply in this context.

Second, in contrast to previous studies of crime and place which have typically analyzed police recorded crime data, in this study, primary data collected using a place-based victimization survey are analyzed to examine patterns. This is important, since not all crime is reported to the police (e.g. Skogan 1984) and thus reporting biases may distort patterns of crime portrayed by police recorded crime data. While prior studies have examined patterns of victimization at the household level using data collected from national surveys (see SooHyun et al. 2017), these surveys lack the detail necessary to examine patterns of concentration for other units of analysis such as street segments and neighborhoods. As far as we are aware, our survey is the first to enable such comparisons.

Using data from an extensive place-based crime victimization survey, the distribution of two crime types - breaking-and-entering $(\mathrm{B} \& \mathrm{E})$ and domestic theft—are analyzed at the household, street segment and neighborhood levels. In doing so, variants of a Lorenz curve and Gini index (GI) are used to examine: (a) whether crime concentrates at these different spatial scales; and, (b) if such concentration reflects anything beyond the spatial distribution of opportunity for these types of offenses.

The remainder of the article is organized as follows. The next section provides a brief review of research concerned with crime concentration at place. This is followed by a description of the study area, the approach to primary data collection, the analytic strategy, and an analysis of the findings. The paper concludes with a discussion of the findings as they relate to criminological theory and crime reduction practice. 


\section{Concentration of Crime at Place}

Examining the degree to which crime concentrates at micro-places within cities has gained considerable research attention in the last 30 years, and reviews of the available evidence suggest that urban crime concentrates across a range of crime types, and at different spatial scales (Telep and Weisburd 2018; Eck et al. 2017). For example, using a year-long record of emergency calls to the police in the city of Minneapolis (US), Sherman et al. (1989) found that while around $60 \%$ of addresses in the city generated all emergency calls, just $3.5 \%$ produced $50 \%$ of them. The concentration of crime was found to be even greater when the patterns observed for specific crimes were analyzed separately. In the case of predatory crimes for instance, all robbery, auto thefts and rape or criminal sexual conduct (CSC) related calls were generated by less than $3 \%$ of all places. Using data for emergency calls to the police in the city of Boston (US) for a five-year period, Pierce et al. (1988) also found that only $3.6 \%$ of addresses produced $50.1 \%$ of all calls to the police. Such studies provide evidence to suggest that crime is highly concentrated.

In a longitudinal study of crime across street segments in the city of Seattle, US, Weisburd et al. (2004; see also Weisburd et al. 2012) investigated the extent to which crime concentrated at place, and the stability of such concentration over time. They found that, for each year between 1989 and 2002, all crime incidents in the city occurred within 47-53\% of street segments. Remarkably, only $4-5 \%$ of street segments in the city generated $50 \%$ of all crime incidents each year. The approach employed in this study (Weisburd et al. 2004) has since been replicated in other cities, including locations outside of the US, with strikingly similar findings (for example see Weisburd 2015; Curman et al. 2015).

For example, in a more recent study in the city of Vancouver, Andresen et al. (2017) investigated the patterns observed for eight different crime types over a 16-year period. For all offense types considered, crime was found to be highly concentrated at street segments and intersections - although there was clear variation in the degree of concentration across different crime types. For instance, only $7.11 \%$ (or $1.02 \%$ ) of street segments accounted for all (or 50\%) of robbery, while $31.27 \%$ (or 5.37\%) of street segments and intersections accounted for all (or 50\%) of burglaries during the same year. Braga et al. (2011) also found that only $2 \%$ of street segments and intersections in the city of Boston accounted for $50 \%$ of robbery incidents between 1980 and 2008. In all of these cases, regardless of the crime type, or whether all crime types were aggregated or not, crime was highly concentrated at the micro level of place.

Most research concerned with crime and place has been conducted in the U.S., Canada, or Europe. However, Mazeika and Kumar (2017) recently examined crime concentration in the city of Jaipur (India) - a city in a developing country with different ecological and physical settings to the studies so far discussed. They found that crime was concentrated at places in this context too. For instance, four hotspots representing less than $1 \%$ of the total land in the study area accounted for about $23 \%$ of burglary incidents. In their study, de Melo et al. (2015) studied patterns of concentration for two crime types-robbery and theft-using data for the city of Campenes in Brazil. They also found that crime was highly concentrated at places. Consistent with the findings discussed above, $50 \%$ of crime occurred on only $3.7 \%$ of street segments.

This consistency across studies is an important aspect of Weisburd's (2015, p. 138) law of crime concentration, and he states that "for a defined measure of crime at a specific microgeographic unit, the concentration of crime will fall within a narrow bandwidth of percentages for a defined cumulative proportion of crime". In their recent review of the 
evidence, Telep and Weisburd (2018) show (for example) that across the 15 studies they reviewed, with data for 21 cities (see Table 1, p. 589), 50\% of crime occurred on between 1.7 and $7.8 \%$ of street segments.

It is important, however, to note that most crime at place studies-with exceptions to include Sherman et al. (1989), Johnson and Bowers (2010), and Davies and Johnson (2015) - are mostly descriptive in the sense that they do not show whether the concentration of crime at places exceeds expectation, given the distribution of crime opportunity. However unlikely, for such studies it is possible that the occurrence of concentration might reflect nothing more than the distribution of crime opportunity. Also worth noting is the fact that these studies use data on calls for service or crimes recorded by the police, which are subject to issues of under-reporting (e.g. Skogan 1984; Langton et al. 2017).

Nonetheless, the overwhelming evidence from prior research demonstrates that patterns of crime are concentrated. However, except for the few studies discussed above, little is known about patterns of crime concentration at place outside Western Europe and North America. As far as we are aware, nothing is currently known about patterns of crime in sub-Saharan Africa, for example. Perhaps the challenges faced by researchers in these regions, particularly with regards to the availability of reliable and appropriate data, makes comprehensive research harder to undertake, but this does not absolve the need for more empirical testing of the universality of the law of crime concentration at place. The current paper aims to address this gap.

\section{Scale and Aggregation Effects on the Concentration of Crime}

The importance of analyzing crime trends at smaller spatial units has long been recognized (for example: Glyde 1856), but it was not until recently that empirical testing of the degree to which urban crime varies across different geographical scales has been explicitly examined (see Johnson 2010; Andresen and Malleson 2011; Steenbeek and Weisburd 2015; Rosser et al. 2017). For instance, in their study, Andresen and Malleson (2011) tested the stability of crime patterns in Vancouver over a 10-year time span at three different spatial scales-census tracts, dissemination areas, and street segments. They found that while the concentration of crime at places was observed at all spatial scales, the patterns observed at larger spatial units (i.e. census tracts and dissemination areas) were dictated by the concentration at the street segment level.

More recently, Steenbeek and Weisburd (2015) studied over 400,000 police crime records spanning a nine-year period in the city of The Hague. They compared crime concentration at the street segment, neighborhood and district levels. They found crime to be more concentrated at the street segment level than at neighborhoods or districts. For example, reporting on the percentage of spatial units that accounted for $50 \%$ of crime in the city, they found that during the year $2009,50 \%$ of all crime incidents occurred on only $6.83 \%$ of street segments compared to $20.18 \%$ of neighborhoods and $20.45 \%$ districts. Additionally, while all districts (100\%) and almost all neighborhoods (99.12\%) had experienced at least one crime incident over the same period, only $52.28 \%$ of street segments did. Moreover, the degree to which crime concentrated, and the variability of such concentration across spatial units was found to be stable over the period of time studied. Using a Linear Mixed model approach to test for the variability of crime across different spatial units, the authors attributed much of the variability in crime to the street segments, concluding that microlevel units are important to understanding the pattern of crime across urban space. 
The findings that have so far emerged from recent studies tend to favor the use of street segments or other smaller places as the unit of analysis for criminological enquiry. Street segments (or blocks), for instance, are seen as "behavioral settings" (Wicker 1987) or micro-communities (Weisburd et al. 2012) where neighbors often interact and social control is assumed to be most effective, as well as places that influence the manifestation of crime opportunities. As such, street segments have been adopted as important units of analysis in the study of crime at places (e.g. Taylor 1997; Weisburd et al. 2012).

As well as informing theory, understanding patterns of crime has practical implications for policing. Of particular importance is the fact that police resources are limited and cannot be deployed everywhere. In the event that crime is highly concentrated, then a rational allocation of resources would be to deploy patrols (or other efforts) to high crime or "hotspot" locations. Over the last few decades, several studies have examined the effectiveness of such strategies and Braga et al.'s (2014) systematic review of them suggests that hotspots policing reduces crime in hotspots without displacing it to other areas nearby (see also, Bowers et al. 2011; Weisburd and Majmundar 2018). With respect to optimizing such strategies, a natural question concerns how large identified hotspots should be. If they are too small, they may not provide sufficient coverage to encapsulate the problem. If they are too large, resources will be spread too thin and the effects of policing diluted. While hotspot areas identified for policing are often small, studies of geographically focused policing interventions have examined the effects of policing in areas of varying size (see Bowers et al. 2011). Consequently, understanding the spatial scale(s) at which crime concentration occurs is of both academic and practical importance.

In summary, urban crime is found to concentrate in space, and of the spatial units of analysis used in prior studies, micro units of analysis such as street segments are found to explain much of the concentration of crime within cities. However, almost all research on this issue has examined patterns in Euro-American settings. In the present study, we examine the distribution of crime in the context of Nigeria, to see if: (1) crime concentrates at the household, street segment and neighborhood units of analysis more than would be expected on a chance basis (Hypothesis 1); and, (2) there is evidence to suggest that in this setting crime is more concentrated at smaller units of analysis (Hypothesis 2).

\section{Data and Methods}

\section{The Present Study}

The present study was conducted in the city of Kaduna, Nigeria. The city serves as an important regional transportation hub and is considered to be the symbolic political capital of Northern Nigeria (Bununu et al. 2015). Unlike the typical pre-colonial cities in the country that are characterized by conservative traditional urban settings, Kaduna exhibits influences of western town planning (a map of the city is shown in Fig. 1).

\section{Police Incident Reports}

Police incident reports, particularly in developing countries such as Nigeria, only represent a fraction of the total number of committed offenses (Gyong 2010; Ayodele and Aderinto 2014). In addition, the lack of a comprehensive address register means that the majority of 


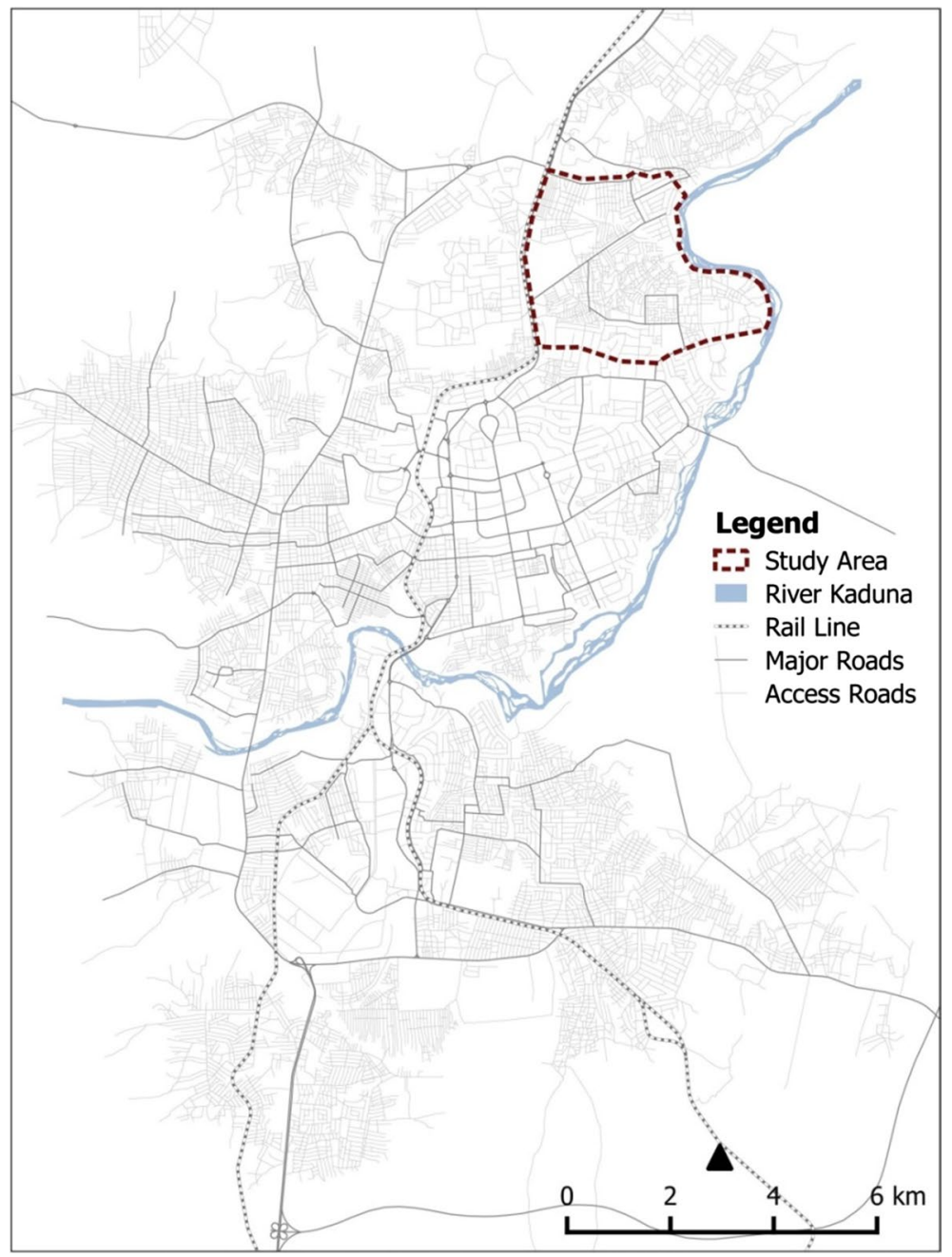

Fig. 1 A map of Kaduna Metropolis

police incident reports in Nigeria cite a nearby landmark (e.g. a market, place of worship or local neighborhood name) rather than the specific address of an incident. This presents a major challenge for the accurate geocoding of police crime data. Moreover, official incident reports in Nigeria have been subject to controversy (Alemika and Chukwuma 2005) for instance, there have been cases involving the manipulation of records to satisfy individual, political and or institutional interests. Consequently, official crime data in Nigeria would likely represent a biased sample of offenses. For this reason, and because such data were not available, primary data were collected using a place-based victimization survey. 


\section{Primary Data}

In light of the above, primary data were collected using three methods-(a) a field mapping exercise to create a base map of the study area to enumerate the number and location of all residential properties (households) and other buildings; (b) a Block Environmental Inventory (BEI) to obtain data on the condition of the built environment (see Perkins et al. 1992); and (c) a place-based household and crime victimization survey to collect data on a range of demographic variables and to obtain data on the rate of crime victimization for the study period of 1 year. The fieldwork and survey were conducted between April and May 2014. Here, we describe the methods and data collected as part of the field mapping exercise and victimization survey.

Due to available resources, it was not practical to survey the entire city of Kaduna, and so the present study is limited to two urban districts: Badarawa-Malali and part of Kawo, both of which are highlighted in Fig. 1. These two districts were selected because there is considerable variation within them in terms of the physical and social settings of the residential neighborhoods they contain. Broadly, there are three distinct types of residential neighborhoods within the study area, these being high, medium and low-density residential neighborhoods. The high-density residential areas, also referred to as urban villages (see MLCN 2010), account for almost 50\% of the total residential land use. These areas have no formal physical planning and are characterized by irregular plot layouts with narrow streets that are mostly unpaved. Despite being the most deprived communities, these areas have the strongest traditional community identity, which (theoretically) encourages neighbors to care for each other. In contrast, the low and the medium density residential areas exhibit western influences of physical planning. The streets are wide and mostly paved, with regular sized plots aligned and well-arranged on large street blocks. The most affluent groups in the population live in these areas-however, traditional community identity is weaker in these areas than in the others (MLCN 2010). No other districts in the city of Kaduna would provide better variation, which made the areas selected ideal for studying patterns of urban crime.

The estimated population of the study area is 137,540 people, who reside in 13,865 households (MLCN 2010). This represents $12 \%$ of the total population of Kaduna and 13\% of all households in the city. The average household size is about 9.91 persons per household, which is similar to the city average of 9.88 , but rather different to cities in the U.S. and Europe, for which the average household size is currently about $2.5{ }^{1}$ Another issue of particular note is that, in contrast to Euro-American settings, for which a household typically houses a single nuclear family (parents and their children), in Nigeria households often contain more than one family.

\section{Study Area Base Map}

To produce a base map of the study area, the area was divided into 88 map sections, and a paper map printed for each. Enumerators conducted site visits and used pencils to trace out the boundaries of all properties on the paper maps so as to best reflect the actual boundaries as observed in the field. A unique reference number (URN) was

\footnotetext{
1 See: www.census.gov/data/tables/time-series/demo/families/households.html; www.ons.gov.uk/peopl epopulationandcommunity/birthsdeathsandmarriages/fmilies/bulletins/familiesandhouseholds/2016. Last accessed 25 November 2018.
} 
assigned to each property to allow the integration of all datasets in a Geographic Information System (GIS). The boundaries produced (and associated URNs) were subsequently digitized in QGIS 2.12 with the aid of the Google Satellite OpenLayers plugin.

\section{Place-Based Victimization Survey}

Following the field mapping exercise, a 44-item structured questionnaire interview was developed to collect data on (1) crime victimization and (2) demographic variables. In relation to victimization, respondents were asked about their experience of crime in the previous 12 months. Here, we focus on the crimes of breaking and entering (B\&E) and domestic theft as these could be geolocated to a specific address. The former is defined as an incident that involves forceful breaking into a property with the intention to steal, while the latter is an offense of stealing from a property without breaking in. In what follows, we analyze the data for the two offense types together, but note that analyzing them individually leads to the same conclusions.

To conduct the survey, houses were selected from within the study area using systematic random sampling whereby one adult of every $k$ th household was approached to participate in the survey, regardless of the number of families living in that household. In completing the survey, participants were asked to respond to questions about all families living in their household. A total of 3294 households were interviewed but only those data from 2932 of the surveys were included in the analysis. Data were excluded for the following reasons: 105 responses were rejected either because no URN was recorded, or because the URN duplicated an existing record, while 257 respondents declined to respond to most (or all) questions during the interview. The non-response rate was consequently just $7.8 \%$.

To enable the geocoding of the survey data (and the aggregation to different units of analysis), the URN for each sampled property was noted on the corresponding questionnaire. This was then cross referenced with the field mapping data to generate a dataset that included the XY-coordinates for each of the sampled properties. Figure 2 shows the XY-coordinates of all sampled households, while a Kernel Density surface (see, Chainey and Ratcliffe 2005; Eck et al. 2005; Chainey et al. 2008), used to preserve the anonymity of the exact victim locations, shows the distribution of crime incidents.

\section{Units of Analysis}

Three units of analysis are considered in this study-(a) households, (b) street segments, and (c) neighborhoods. To enable aggregation, in addition to recording the URN for every household in the study area, each property was assigned a reference code for the street segment, and the neighborhood in which it was located.

\section{Street Segments}

Following Weisburd et al. (2012), a street segment is defined here as the two faces of a city block between any two intersections. As a consequence of the urban form of the study setting, it should be noted that some street segments have as little as one household on them. Additionally, it is important to note that, unlike settings in 


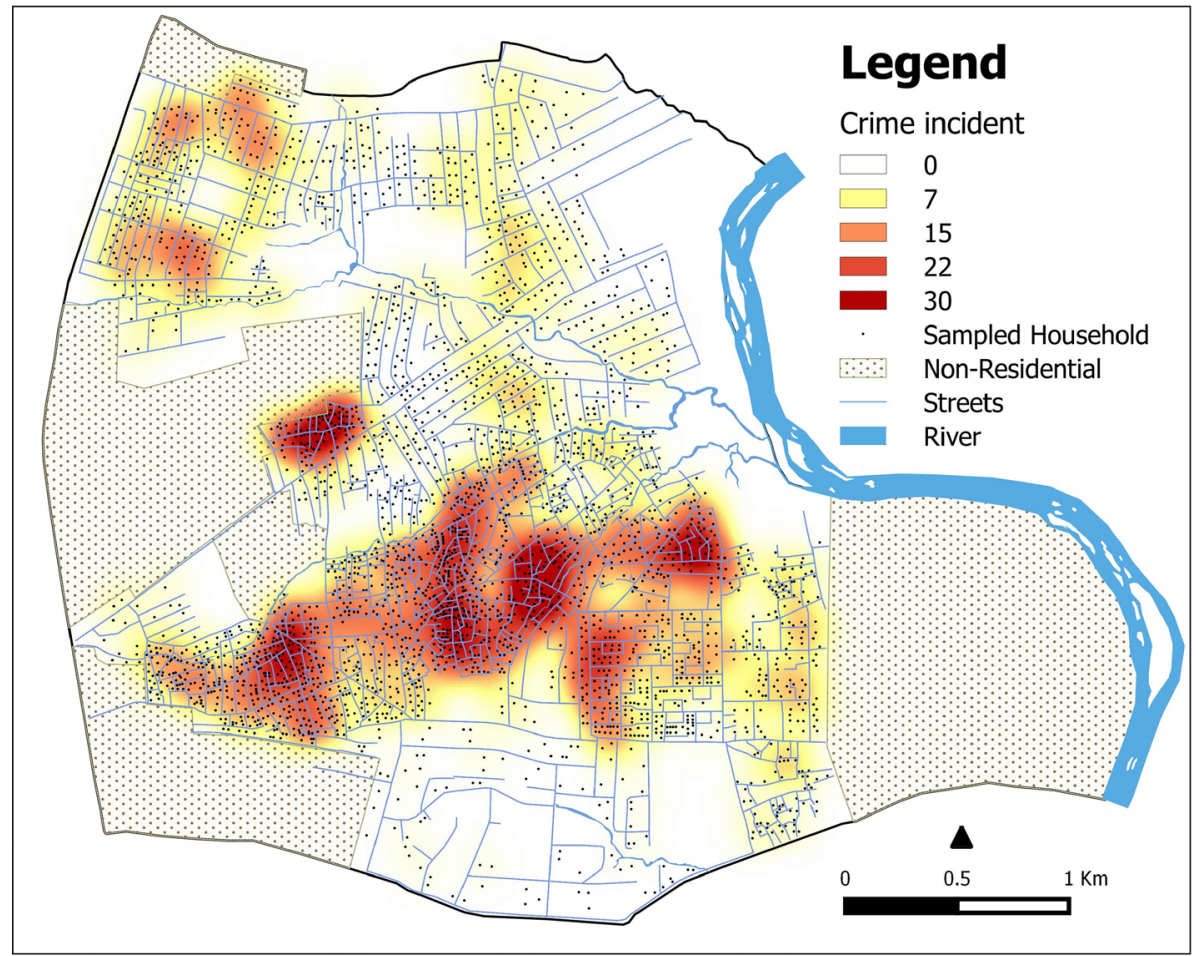

Fig. 2 Distribution of sampled households and locations of reported crime in Badarawa-Malali. Note: The KDE surface was generated in QGIS 2.18 using $6.38492 \mathrm{e}-05$ by $6.38492 \mathrm{e}-05 \mathrm{~m}$ cells, a $200 \mathrm{~m}$ spatial bandwidth and five thematic classes defined using a continuous classification

Euro-American cities, the majority of streets are untarred, which affects the smooth flow of traffic.

There were 1117 street segments in the study area. Of those, only 751 had residential properties located on them. Knowing this is important since absent this information, crime might appear to be concentrated even if it merely reflected the distribution of opportunity. The remaining street segments either hosted only non-residential properties (including vacant land or properties under construction), or just served to connect two streets (with no households located on them). Survey data were only collected and patterns explored for those street segments that had households on them. The street segments (see Fig. 3) have an average length of $135.61 \mathrm{~m}$ and a standard deviation of $125.15 \mathrm{~m}$.

\section{Neighborhood Boundaries}

It is worth noting that the areal units often used in analyses at the meso-level (e.g. neighborhoods) in the crime and place literature are administrative boundaries (for example see: Andresen and Malleson 2011; Steenbeek and Weisburd 2015). While convenient, these boundaries are usually created to serve purposes other than scientific or social research 


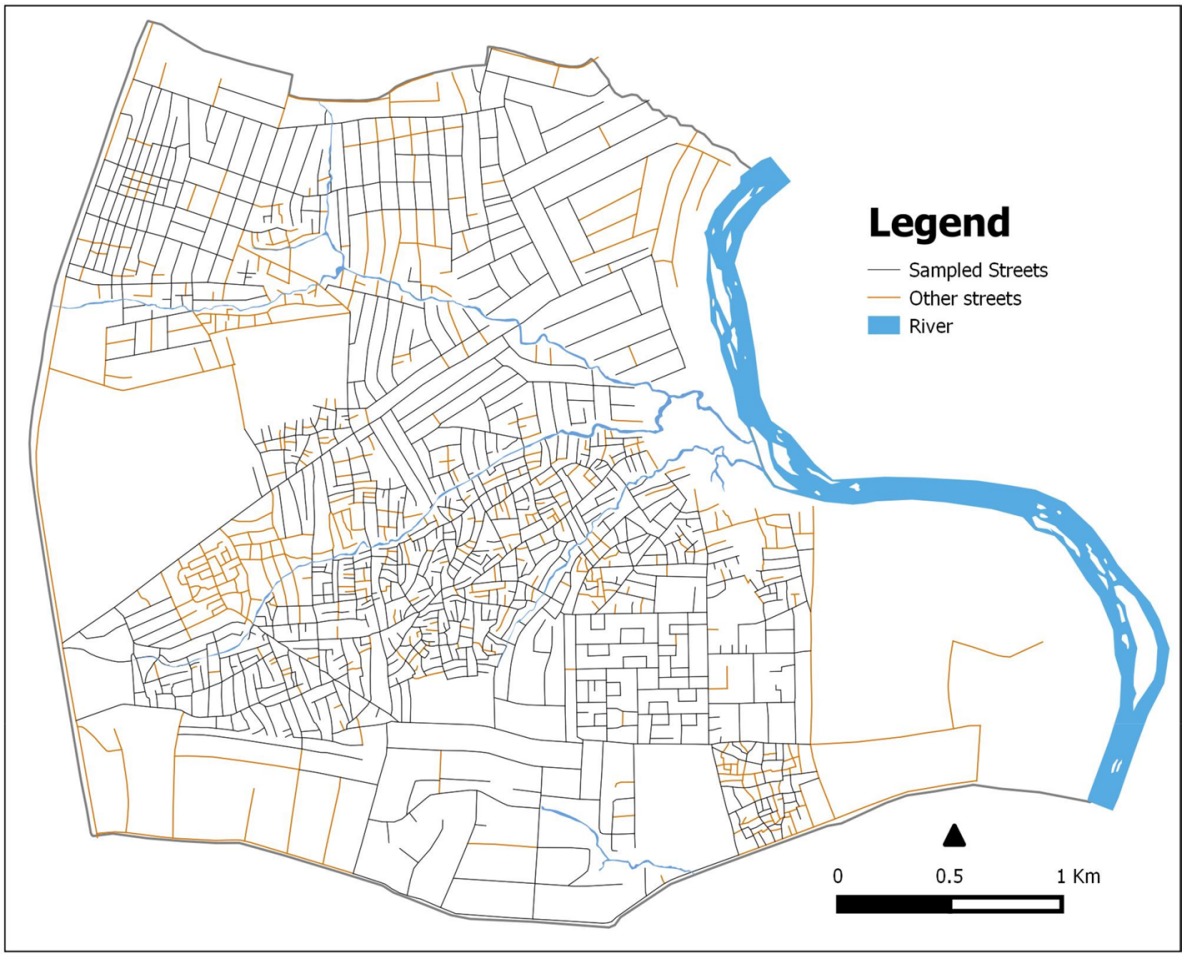

Fig. 3 Street segments with (and without) residential properties

and may therefore encapsulate highly diverse populations and urban characteristics. This can potentially undermine the analysis of areal units. Furthermore, no small administrative area boundaries (i.e. neighborhood proxies) exist in Nigeria and hence we had to create our own. A variety of approaches could be used to do this, but the one adopted here aimed at simultaneously minimizing the internal variance within neighborhoods and emphasizing the differences between them. Needless to say, however, that a potential challenge with any such exercise is what has become known in the literature as the Modifiable Areal Unit Problem (MAUP) - that changing a boundary set can lead to different conclusions (see: Openshaw and Taylor 1979; Fotheringham and Wong 1991).

It is important to also note that there is no standard definition of a neighborhood in terms of either population size or geographical extent. The neighborhood units constructed here, however, are closely based on Harvey Zoubargh's concept of a "natural area"- "a geographical area characterized both by a physical individuality and by the cultural characteristics of the people who live in it" (Zorbaugh [1926] in Lin and Mele 2005: p. 85). The approach used involved the application of the following neighborhood demarcation rules:

- Neighborhoods were delineated in terms of housing density-with regions of high, medium and low density identified based on the number of properties per unit of geographical area.

- Following natural boundaries such as streams and rivers that would naturally divide a neighborhood. 


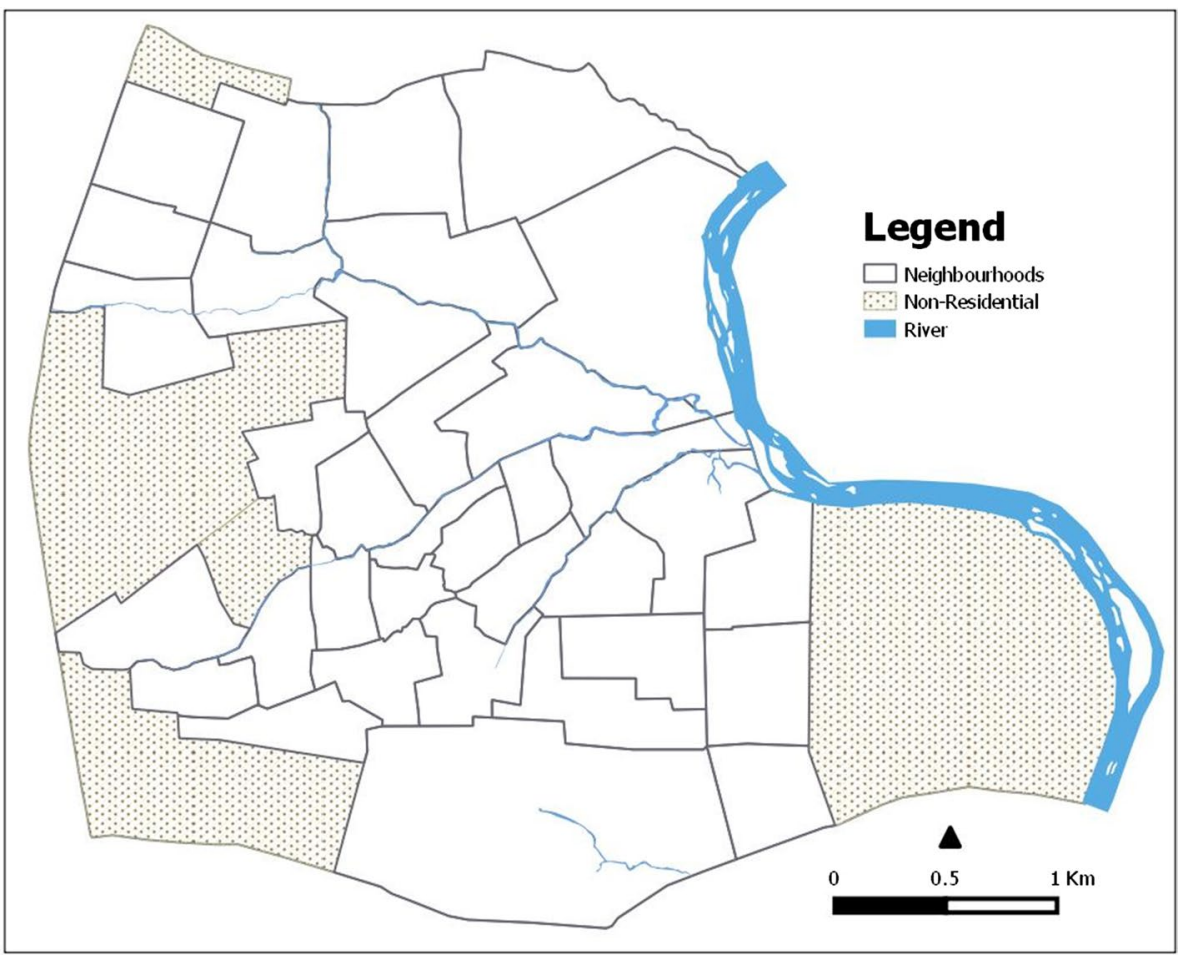

Fig. 4 Neighborhood boundaries

- Considering physical manmade features such as major roads that would also physically divide a neighborhood.

An iterative process was repeated until each neighborhood so defined contained a population of between 4000 and 6000 people to reflect the range generally used in prior studies to define a neighborhood (i.e. U.S. census tracts have populations of about this size ${ }^{2}$ ). Figure 4 shows the resulting neighborhoods that were identified. A total of 40 neighborhoods were defined, of which 36 could be considered residential neighborhoods (the other neighborhoods housed institutional and public landuses-i.e. schools, commercial areas and government offices). However, data were collected in only 35 neighborhoods as a survey in one neighborhood had to be abandoned for reasons of enumerator safety.

\section{Results}

In this Section, patterns of crime concentration were examined at the three spatial scales discussed above: household, street segment and neighborhood. Descriptive statistics are presented and then analyses conducted to determine whether any patterns observed exceed

${ }^{2}$ See: https://www.census.gov/geo/reference/gtc/gtc_ct.html. Last accessed 24th October, 2018. 
Table 1 Percentage of spatial units accounting for $50 \%$ of crime

\begin{tabular}{llll}
\hline Spatial unit & $\begin{array}{l}\text { (a) \% that have any } \\
\text { crime }\end{array}$ & $\begin{array}{l}\text { (b) \% accounting for 50\% of } \\
\text { all crime }\end{array}$ & $\begin{array}{l}\text { (c) \% with crime that } \\
\text { account for 50\% of } \\
\text { crime }\end{array}$ \\
\hline Household & 38.13 & 8.32 & 21.82 \\
Street segment & 66.78 & 11.25 & 17.11 \\
Neighborhood & 100 & 27.14 & 27.14 \\
\hline
\end{tabular}

that which would be expected given the distribution of surveyed crime opportunities (households). Table 1 follows the approach taken by Andresen and Malleson (2011; see also Steenbeek and Weisburd 2015; Telep and Weisburd 2018) to show the percentage of spatial units that account for all and $50 \%$ of crime incidents.

As seen in Table 1, crime was not reported to have occurred at all households or street segments—-some are "crime-free" places. In contrast, crimes were reported for all neighborhoods. Compared to neighborhoods, a much smaller percentage of street segments accounted for $50 \%$ of all crime incidents. Similarly, compared to street segments, a relatively smaller percentage of households accounted for $50 \%$ of all crime incidents. However, when we consider only the units of analysis with crimes that accounted for $50 \%$ of incidents, crime is less concentrated at households compared to street segments, and almost the same as neighborhoods. It is important to note that the descriptive analysis presented above only considers the number of crimes recorded for each unit of analysis-different street segments or neighborhoods, however, will not have the same numbers of sampled households - consequently, the opportunity for crime will not be evenly distributed across them. To address this issue, and to provide a more complete picture of observed patterns, we derive variations of the Lorenz curve (Lorenz 1905) to examine the degree to which crime concentrates at each spatial scale whilst taking account of the number of crime opportunities across them.

Lorenz curves have traditionally been used in the field of economics to test for evidence of income inequality (Lorenz 1905; Bakare 2012). In this context, after ranking the population in terms of wealth (from lowest to highest), Lorenz curves are used to show the cumulative percentage of income that is possessed by the (least wealthy) cumulative proportion of the (ranked) population. Where the observed line falls beneath the $45^{\circ}$ line of equality (for which $\mathrm{X} \%$ of the population account for $\mathrm{Y} \%$ of wealth), this provides evidence of inequality. This method has also been used in the context of crime (e.g. Tseloni and Pease 2005; Eck et al. 2017; Lee et al. 2017) to show that crime is not evenly distributed across (for example) households. However, as the data are ranked from the least to most at risk, this format of presentation is not particularly intuitive. That is, the reader has to undertake simple but necessary calculations to determine what fraction of crime is experienced by a particular percentage of victims, or other unit of analysis. ${ }^{3}$ For this reason, we follow the approach taken in other studies of crime concentration (Johnson and Bowers 2010; Davies and Johnson 2015; Steenbeek and Weisburd 2015). These employ the same process used to generate Lorenz curves, but the spatial units (households, street segments or neighborhoods) are ranked from highest to lowest (instead of the other way around) according to the

\footnotetext{
3 The reader cannot simply look along the $\mathrm{x}$-axis and then trace the curve to discover what fraction of crime is experienced by those most at risk since the data are not sorted in the right order to do this.
} 

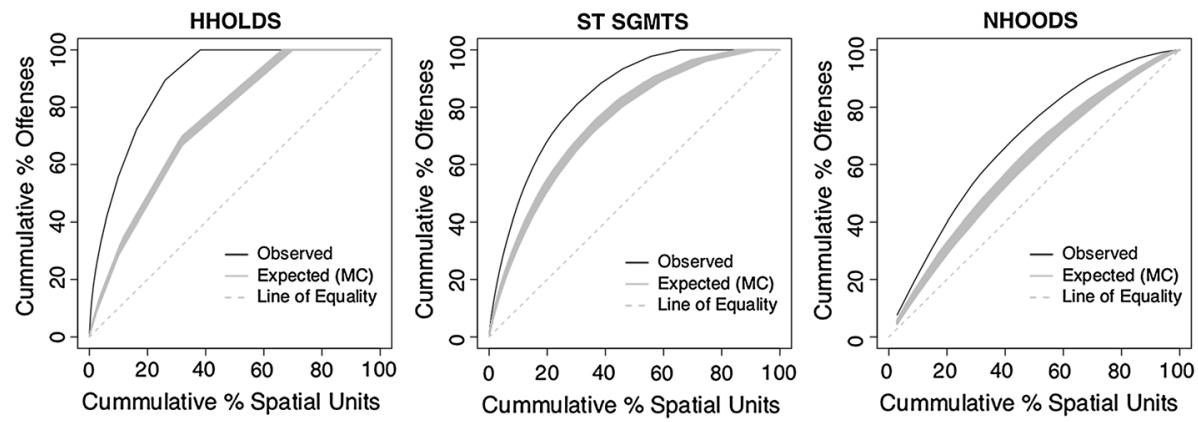

Fig. 5 Cumulative concentration curves for residential property offences and for different spatial units. Note: households (HHOLDS); street segments (ST SGMTS); neighborhoods (NHOODS)

count of crime reported at, on or in them. A cumulative concentration curve is then generated by plotting the cumulative percentage of crime experienced by the corresponding cumulative percentage of spatial units (households, streets or neighborhoods). This curve then shows what fraction of crime is accounted for by a particular percentage of households, street segments or neighborhoods.

Only those street segments $(\mathrm{N}=751)$ and neighborhoods $(\mathrm{N}=35)$ with one or more residential properties were included in the analyses. Including those with no households would exaggerate the extent to which crime is concentrated. The plots shown in Fig. 5 illustrate the degree to which crime was concentrated at the household, street segment and neighborhood. These figures are simple to interpret and show, for example, that about $50 \%$ of incidents occur on about $11 \%$ of street segments. This is very different to the "naïve" line of equality which shows the expected distribution, derived assuming that the risk of crime is equal across spatial units. This approach has been used in recent studies that have used Lorenz curves to quantify crime concentration (e.g. Johnson and Bowers 2010; Davies and Johnson 2015; Steenbeek and Weisburd 2015).

In addition to using this simple line of equality, we calculated the expected distribution using a Monte Carlo simulation, assuming that the risk of victimization is uniformly distributed across households. Doing so controls for the fact that different street segments and neighborhoods will have different numbers of households located on or in them. It also addresses a known shortcoming associated with the Lorenz curve. That is, as pointed out by Bernasco and Steenbeek (2017), the Naïve use of Lorenz curves can exaggerate the degree to which crime is interpreted as concentrating if the number of places considered (i.e. units of analysis such as street segments or neighborhoods) is greater than the number of crime incidents. Given that we compare patterns of concentration for different spatial units (households, street segments and neighborhoods) for which the sample sizes differ substantially, ${ }^{4}$ this would be a problem if not dealt with explicitly. In what follows, the expected distribution is computed so that it is subject to the same constraints as the observed distribution, allowing us to address this issue directly.

To compute the expected distribution, we use a Monte Carlo simulation which is performed in the following way: for each iteration of the procedure $N$ locations, where $N$ is the number of crimes observed in our data set, were selected as synthetic victims from all

$\overline{4}$ There are 2932 households, 751 street segments and 35 neighborhoods. 
of those surveyed, using a uniform random number generator. This selection process was completed with replacement so that households could be "victimized" multiple timesa finding commonly observed in the literature on repeat victimization (e.g. Pease 1998). After each iteration, of which there were 999, a cumulative concentration curve was computed for the synthetic data. This re-sampling process produced a distribution of expected distributions, which are shown in grey in Fig. 5.

The first thing to notice from Fig. 5 is just how different the naïve line of equality is from the expected distribution computed using the Monte Carlo simulation, particularly for smaller spatial units. The reason for this is that the simple line of equality takes no account of the actual number of opportunities across spatial units, whereas the Monte Carlo simulation does. Not addressing this would leave the analysis susceptible to the problem articulated by Bernasco and Steenbeek (2017).

As expected, Fig. 5 shows that crime is more concentrated for smaller units of analysis. However, it also shows that, in contrast to what would be expected assuming a simple line of equality, crime is expected to be more concentrated for smaller units of analysis even if the observed pattern reflected nothing more than the distribution of opportunity. Despite this, Fig. 5 shows that the curves for the observed distribution differ from expectation for all spatial units of analysis (all $p \mathrm{~s}<0.001$ ). What is unclear is whether this departure from expectation is more pronounced for smaller units of analysis.

To examine this issue directly, the Gini index (Gini 1912) was computed for each unit of analysis. This is an index of the area of inequality shown in a Lorenz plot, or the cumulative concentration curve in our case. It is the ratio (A/B) of the area of the chart between the expected line of equality and the observed distribution (let's call this A), and the area of the chart above the expected line of equality (let's call this B-A is a subset of B). Traditionally, where the naïve line of equality is used, the index ranges from 0 to 1 , where a value of 0 indicates that the distribution of crime across spatial units is entirely equal, while a value of 1 indicates the distribution is completely unequal, suggesting that all crime incidents occurred in only one place. However, as we calculate the expected distribution using a MC simulation-accounting for crime opportunity - it is possible for this value to be less than zero in the current analysis. ${ }^{5}$ We compute the Gini index by approximating the two areas ( $\mathrm{A}$ and $\mathrm{B}$ ) by summing the area of the trapezoids defined by each $\mathrm{j}$-unit change along the X-axis (see, Berndt et al. 2003; Johnson and Bowers 2010). The associated formula is shown as Eq. 1.

$$
\text { Gini Index }=\frac{1}{B} \sum_{i=1}^{n}\left[\frac{\left(e_{i}-y_{i}\right)+\left(e_{i-1}-y_{i-1}\right)}{2}\right] \times\left(x_{i}-x_{i-1}\right)
$$

where $e_{i}$ is the expected value of the cumulative proportion of crime for observation $i$ (there are $100 / \mathrm{j}$ observations), $y_{i}$ is the observed value of the cumulative proportion of crime for observation $i$; $x_{i}$ is the cumulative proportion of units of analysis for observation $i$; and, B is the proportion of the area of the cumulative concentration curve above the expected line of equality. B is calculated using the second part of Eq. 1 but with a constant expected value of 1 .

Computing a Gini Index for each of the iterations of the Monte Carlo Simulation discussed above allows us to plot their distribution (see Fig. 6) and to calculate the (pseudo)

\footnotetext{
5 That is, a realization of the MC simulation may produce a distribution that while random, exhibits more concentration than is observed in the empirical data.
} 
Fig. 6 Distributions of the Gini coefficients generated by the MC Simulation for different spatial units of analysis. Note: households (HHOLDS); street segments (ST SGMTS); neighborhoods (NHOODS)

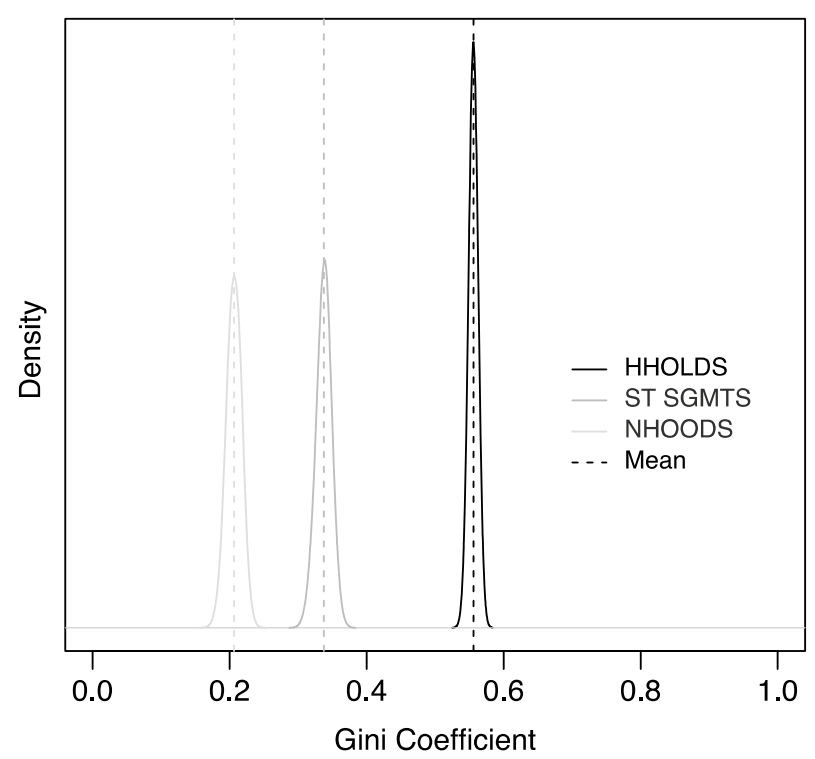

probability of observing the empirical value, assuming the null hypothesis that the observed and expected values are equivalent. The (pseudo) $p$ value is calculated using the formula shown in Eq. 2. In this case, $n$ is the number of iterations of the Monte Carlo simulation (in this case, 999), and $r$ is the number of realizations for which the value of the test statistic is less than or equal to zero.

$$
p=\frac{n-r+1}{n+1}
$$

Figure 6 shows that having accounted for expectation, given the distribution of opportunity, crime was most concentrated at the household level, followed by street segments and then neighborhoods. Considering statistical significance, the degree of concentration was significant for all units of analysis (all $p s<0.001$ ). Moreover, the distributions of the Gini indices generally do not overlap, which indicates that the differences observed for the different units of analysis were statistically significant. That is, crime becomes significantly more concentrated as we move down the cone of spatial resolution.

\section{Discussion}

As far as we are aware, this study provides the first empirical analysis of the concentration of crime at the micro level of place in the context of sub-Saharan Africa. This study is also noteworthy in that it represents a rare example for which the concentration of crime was studied at a range of spatial scales using a survey designed specifically for this purpose. That is, most studies that use survey data explore patterns at the national level, and most studies that examine crime concentration use secondary sources of data. Our findings demonstrate that, despite the study area representing a radically different context to the types of areas studied hitherto, and using survey data rather than police incident report or calls for service data, the patterns observed are remarkably similar to those found elsewhere. 
To put this into context further, we compare some of the current findings to those of prior studies that have used police recorded crime data for Euro-American settings. Recall that in their study, Sherman et al. (1989) found that around 11\% (and 3.31\%) of all addresses in the city of Minneapolis accounted for all (and 50\%) of burglary incidents within a 1-year period. In the current study, the most appropriate comparison is with the category of breaking and entering. ${ }^{6}$ In this case, we find very similar results, with $15.6 \%$ and $3.8 \%$ of households accounting for all and $50 \%$ of offenses. The similarity in the latter finding is particularly striking given that the data are for very different locations and come from police records in the case of Sherman et al. and a victimization survey here.

When the data were aggregated and analyzed at street segment and neighborhood levels, the patterns were again similar to those reported elsewhere (e.g. Weisburd et al. 2004; Andresen and Malleson 2011; Weisburd 2015; Curman et al. 2015; Weisburd and Amram 2014; Steenbeek and Weisburd 2015). For example, in the city of The Hague, $50 \%$ of all crimes occurred on $7.28 \%$ of street segments and in $20.18 \%$ of neighborhoods (Steenbeek and Weisburd 2015). Additionally, while around 52\% of street segments experienced at least one crime, almost all (99.12\%) of neighborhoods did. Similar findings are found here-around $11 \%$ (and 65\%) of street segments accounted for 50\% (and all) crime incidents (incidents of Theft and B\&E) while around 29\% (and 100\%) of neighborhood accounted for $50 \%$ (and all) crime incidents. That the findings are similar is in line with Weisburd's (2015) suggestion that "the concentration of crime will fall within a narrow bandwidth of percentages for a defined cumulative proportion of crime".

However, it is worth noting that the percentage of spatial units that account for $50 \%$ of crimes is slightly higher in the present study (e.g. $11 \%$ vs. $2-7.8 \%$ for street segments) than has been observed elsewhere (see Telep and Weisburd 2018). With respect to this, at least three factors might explain the variation. The first is that the patterns may differ due to contextual differences. For example, the condition and settings of the street network or "urban backcloth" (Brantingham and Brantingham 1993) in Kaduna differ greatly to the typical settings in Euro-American cities. In Kaduna, streets are narrow, winding and many are untarred, factors that could influence the pattern of both vehicular and pedestrian movement, and consequently patterns of crime (Davis and Bishop 2013). The second is that the differences may be explained by the fact that here we focus on a particular subset of crime, whereas the figures we cite from Telep and Weisburd's review relate to findings for studies that examine total crime. The third is that the differences may be explained by the fact that the data analyzed here were collected using survey sampling, whereas that analyzed in all previous studies comes from secondary sources, such as calls for police service. As discussed above, it is well known that much crime goes unreported to the police, and that survey methods provide a more complete picture of victimization. These differences in coverage could easily explain the small differences in results observed here. To assess this, future research might examine this issue in jurisdictions where both police and survey data are available.

In addition to examining whether crime was concentrated at various spatial scales using descriptive statistics, we used Monte Carlo simulations to test whether the observed patterns could be explained by the distribution of crime opportunity (i.e. housing units). This was not the case, which indicates the robustness of the findings. Unfortunately, researchers

\footnotetext{
6 Theft from the household does not require an offender to break into a home and is common in Nigeria because, unlike residents in the U.S. and European cities, the majority of Nigerians commonly leave their households unlocked.
} 
do not typically use such methods, but given their simplicity we would encourage them to do so. For crimes that do not occur at discrete locations such as households, it will be a little more complicated to enumerate the crime opportunities present, but a simple proxy that could be used for street segments would be the length of road in question. Other possibilities exist.

Having demonstrated that crime is concentrated in a Nigerian urban setting, the next research challenge will be to explain it. Given the differences between Nigeria, the US and other countries, it may be that different factors explain the patterns observed in that country and elsewhere. Regardless, what the current findings suggest is that, while neighborhood effects should not be ignored, explanations should be sought at the micro-level of place, where places include street segments and even smaller spatial units of analysis (see also, Weisburd et al. 2012).

In terms of crime prevention, the finding that crime is concentrated in a Nigerian setting suggests that geographically focused policing initiatives may be beneficial in this context too. Increased police patrols represent one option, but other strategies exist and those tailored to the specific context are perhaps likely to have the most impact (for a discussion of the effects of geographically focused problem oriented policing, see Braga et al. 2014; Braga and Bond 2008).

Turning to the limitations of the present study, the data collected here are cross sectional and as such do not permit testing of the stability of crime patterns over time. This means that we were not able to test whether the same fraction of (say) street segments account for (say) $50 \%$ of crime each year. Therefore, to place such findings in the broader crime and place literature, future research should consider the use of datasets that span a longer period of time. The use of police recorded data is one option if such data become available (for example see: Mazeika and Kumar 2017), although caution must be taken when using such data in Nigeria due to the issues discussed above.

Another important issue to note is that the analysis here was limited to the two property-based crimes covered in the survey. It is, of course, possible that different patterns would be observed for other types of crime, and hence future research should explore this. With respect to previous studies concerned with the law of crime concentration, many have examined patterns aggregated across crime types (Weisburd et al. 2004; Curman et al. 2015), and hence it is difficult to directly compare our findings with those. However, others have focused on particular forms of crime or have disaggregated their findings (e.g. Sherman et al. 1989; Andresen and Malleson 2011; Braga et al. 2011; de Melo et al. 2015; Andresen et al. 2017), and our findings are generally in line with these. With respect to future research, to fully explore the law of crime concentration at places, it will be important to analyze data for individual crime types (Andresen et al. 2017). Some crime types, such as those studied here, for example, can only occur at particular places, while the opportunity for other types of crime will be more ubiquitous.

As discussed, the findings presented here have implications for crime prevention and control. They suggest that hotspots policing strategies, at least in theory (see Braga et al. 2014), could reduce crime in settings such as Kaduna. However, implementing such approaches will bring fresh challenges, not least because their effectiveness will dependto some extent at least-on the production of accurate maps of hotspot locations. In cities like Kaduna, the necessary data are not currently digitized, which would present problems and, as discussed, much crime goes unreported to the police. Despite these issues, the current study suggests that such approaches are theoretically worthwhile, which provides the motivation for pursuing them. 
To conclude, our findings show that, consistent with the findings of studies conducted in countries with different urban layouts and cultural contexts, property crime is highly concentrated at the micro level of place in Kaduna-a typical setting in sub-Saharan Africa. Our findings thus provide further support for the ubiquity of Weisburd's law of crime concentration at places. That our findings demonstrate that this pattern persists after accounting for the distribution of crime opportunity raises the question of what might explain the observed phenomenon. It will be for future research to address this and to determine if (for example) the environmental characteristics that make crime more likely in US and European cities also explain crime patterns in cities like Kaduna.

Open Access This article is licensed under a Creative Commons Attribution 4.0 International License, which permits use, sharing, adaptation, distribution and reproduction in any medium or format, as long as you give appropriate credit to the original author(s) and the source, provide a link to the Creative Commons licence, and indicate if changes were made. The images or other third party material in this article are included in the article's Creative Commons licence, unless indicated otherwise in a credit line to the material. If material is not included in the article's Creative Commons licence and your intended use is not permitted by statutory regulation or exceeds the permitted use, you will need to obtain permission directly from the copyright holder. To view a copy of this licence, visit https://creativecommons.org/licenses/by/4.0/.

\section{References}

Alemika EO, Chukwuma IC (2005) Criminal victimization and fear of crime in Lagos Metropolis, Nigeria. CLEEN monograph series no. 1. CLEEN Foundation, Lagos

Andresen MA, Malleson N (2011) Testing the stability of crime patterns: implications for theory and policy. J Res Crime Delinq 48(1):58-82

Andresen MA, Curman AS, Linning SJ (2017) The trajectories of crime at places: understanding the patterns of disaggregated crime types. J Quant Criminol 33(3):427-449

Ayodele JO, Aderinto AA (2014) Nature of crime and crime reporting of victims in Lagos, Nigeria. Int J Criminol Sociol Theory 7(1):1-14

Bakare AS (2012) Measuring the income inequality in Nigeria: the Lorenz curve and Gini co-efficient approach. Am J Econ 2(1):47-52

Bernasco W, Steenbeek W (2017) More places than crimes: implications for evaluating the law of crime concentration at place. J Quant Criminol 33(3):451-467

Berndt DJ, Fisher JW, Rajendrababu RV (2003) Measuring healthcare inequities using the Gini index. In: Proceedings of the 36th Hawaii international conference on system sciences. IEEE Computer Society

Bowers KJ (2014) Risky facilities: crime radiators or crime absorbers? A comparison of internal and external levels of theft. J Quant Criminol 30(3):389-414

Bowers KJ, Johnson SD, Guerette RT, Summers L, Poynton S (2011) Spatial displacement and diffusion of benefits among geographically focused policing initiatives: a meta-analytical review. J Exp Criminol 7(4):347-374

Braga AA, Bond BJ (2008) Policing crime and disorder hot spots: a randomized controlled trial. Criminology 46(3):577-607

Braga AA, Hureau DM, Papachristos AV (2011) The relevance of micro places to citywide robbery trends: a longitudinal analysis of robbery incidents at street corners and block faces in Boston. J Res Crime Deling 48:7-32

Braga AA, Papachristos AV, Hureau DM (2014) The effects of hot spots policing on crime: an updated systematic review and meta-analysis. Justice Q 31(4):633-663

Brantingham PL, Brantingham PJ (1993) Environment, routine and situation: toward a pattern theory of crime. Adv Criminol Theory 5:259-294

Bununu YA, Ludin ANM, Hosni N (2015) City profile: Kaduna. Cities 49:53-65

Chainey SP, Ratcliffe JH (2005) GIS and crime mapping. Wiley, London

Chainey SP, Tompson L, Uhlig S (2008) The utility of hotspot mapping for predicting spatial patterns of crime. Secur J 21(1-2):4-28 
Curman ASN, Andresen MA, Brantingham PJ (2015) Crime and place: a longitudinal examination of street segment patterns in Vancouver, BC. J Quant Criminol 31:127-147

Davies T, Johnson SD (2015) Examining the relationship between road structure and burglary risk via quantitative network analysis. J Quant Criminol 31:481-507

Davis TP, Bishop SR (2013) Modelling patterns of burglary on street networks. Crime Sci 2:10

de Melo SN, Matias LF, Andresen MA (2015) Crime concentrations and similarities in spatial crime patterns in a Brazilian context. Appl Geogr 62:314-324

Eck JE, Chainey SP, Cameron JG, Leitner M, Wilson RE (2005) Mapping crime: understanding hot spots. National Institute of Justice, USA. www.ojp.usdoj.gov/nij

Eck JE, Lee Y, SooHyun O, Martinez N (2017) Compared to what? Estimating the relative concentration of crime at places using systematic and other reviews. Crime Sci 6:8

Fotheringham AS, Wong DWS (1991) The modifiable areal unit problem in multivariate statistical analysis. Environ Plan A. 23(7):1025-1044

Gini C (1912) Variabilità e mutabilita. [Pizetti E, Salvemini T (eds)] Reprinted (1955) in Memorie di metodologica statistica. Libreria Eredi Virgilio Veschi, Rome

Glyde J (1856) Localities of crime in Suffolk. J Stat Soc Lond 19:102-106

Gyong JE (2010) Criminal victimization and the reporting of crime in Kaduna state: towards integrating the victim of crime into criminological discourse. Curr Res J Soc Sci 2(5):288-295

Johnson SD (2010) A brief history of the analysis of crime concentration. Eur J Appl Math 21(4-5):349-370

Johnson SD, Bowers KJ (2010) Permeability and burglary risk: are cul-de-sacs safer? J Quant Criminol 26:89-111

Langton L, Planty M, Lynch JP (2017) Second major reddesign of the National Crime Victimization Survey (NCVS). Criminol Public Policy 16(4):1049-1074

Lee Y, Eck JE, SooHyun O, Martinez NN (2017) How concentrated is crime at places? A systematic review from 1970 to 2015. Crime Sci 6(1):6

Lorenz MO (1905) Methods of measuring the concentration of wealth. Publ Am Stat Assoc 9(70):209-219

Max-Lock Consultancy Nigeria (MLCN) (2010) Kaduna master plan: draft final report. Max-Lock Centre, University of Westminster

Mazeika DM, Kumar S (2017) Do crime hot spots exist in developing countries? Evidence from India. J Quant Criminol 33(1):45-61

Openshaw S, Taylor P (1979) A million or so correlation coefficients: three experiments on the modifiable areal unit problem. In: Wrigley N (ed) Statistical applications in the spatial sciences. Pion, London, pp 127-144

Pease K (1998) Repeat victimisation: taking stock. Crime prevention and detection series paper 90. Home Office, London

Perkins DD, Meeks JW, Taylor RB (1992) The physical environment of street blocks and residents perception of crime and disorder: implication for theory and measurement. J Environ Psychol 12:21-34

Pierce G, Spaar S, Briggs LR (1988) The character of police work strategic and tactical implications. Center for Applied Social Research, Boston

Rosser G, Davies T, Bowers KJ, Johnson SD, Cheng T (2017) Predictive crime mapping: arbitrary grids or street networks? J Quant Criminol 33(3):569-594

Sherman LW, Gartin PR, Buerger ME (1989) Hot spots of predatory crime: routine activities and the criminology of place. Criminology 27:27-55

Skogan W (1984) Reporting crimes to the police: the status of world research. J Res Crime Delinq 21(2):113-137

SooHyun O, Martinez NN, Lee Y, Eck JE (2017) How concentrated is crime among victims? A systematic review from 1977 to 2014. Crime Sci 6(1):9

Steenbeek W, Weisburd D (2015) Where the action is in crime? An examination of variability of crime across different spatial units in The Hague, 2001-2009. J Quant Criminol 32:449-469

Taylor RB (1997) Social order and disorder of street blocks and neighborhoods: ecology, microecology, and the systemic model of social disorganization. J Res Crime Delinq 34:113-155

Telep CW, Weisburd D (2018) Crime concentration at places. In: Bruinsma GJN, Johnson SD (eds) Oxford handbook of environmental criminology. Oxford University Press, New York

Tseloni A, Pease K (2005) Population inequality: the case of repeat crime victimization. Int Rev Victimol 12(1):75-90

Weisburd D (2015) The law of crime concentration and the criminology of place. Criminology 53:133-157

Weisburd D, Amram S (2014) The law of concentrations of crime at place: the case of Tel Aviv-Jaffa. Police Pract Res 15:101-114

Weisburd D, Majmundar MK (eds) (2018) Proactive policing: effects on crime and communities. The National Academies Press, Washington 
Weisburd D, Maher L, Sherman L (1992) Contrasting crime general and crime specific theory: the case of hot spots of crime. In: Adler Freda, Laufer William S (eds) Advances in criminological theory, vol 4. Transaction Publishing, New Brunswick, pp 45-70

Weisburd D, Bushway S, Lum C, Yang SM (2004) Trajectories of crime at places: a longitudinal study of street segments in the city of Seattle. Criminology 42(2):283-322

Weisburd D, Groff ER, Yang SM (2012) The criminology of place. Oxford University Press, Oxford

Wicker AW (1987) Behavior settings reconsidered: temporal stages, resources, internal dynamics, context. In: Stokols D, Altman I (eds) Handbook of environmental psychology. Wiley, New York, pp 613-653

Zorbaugh H ([1926] 2005) The natural areas of the city—-from Ernest W. Burgess (ed.)_-“The Urban Community". In: Lin J, Mele C (eds) The urban sociology reader. Routledge, London

Publisher's Note Springer Nature remains neutral with regard to jurisdictional claims in published maps and institutional affiliations. 